\title{
灌浆期不同水分处理对玉米籽粒蛋白质及其 组分和相关酶活性的影响
}

\author{
张智猛 ${ }^{1}$ 戴良香 ${ }^{1} \quad$ 胡昌浩 $^{2}$ 董树亭 $^{2}$ 王空军 $^{2} \quad$ 宁堂原 $^{2}$ \\ （1 山东省花生研究所,山东青岛 266100）（2 山东农业大学农学院,山东泰安２71018）
}

摘 要 蛋白质作为氮素代谢的终极产物, 与玉米 (Zea mays) 籽粒品质呈正相关关系, 其生物合成主要在硝酸还原 酶 (NRase)、谷氨酰胺合成酶 (GS)、谷氨酸脱氢酶 (GDH) 等一系列酶催化下完成, 受制于品种自身遗传特性及环境因 素 栽培管理措施和生态环境条件对玉米品质具有十分重要的影响。关于土壤水分供应状况对玉米籽粒主要品质 成分的分布、积累动态和相关酶活性的影响的研究尚少见报道。以两种不同类型玉米:普通玉米 掖单 22' 和高油 玉米 高油 $115^{\prime}$ 为研究对象, 采用防雨棚池栽试验。水分处理以开花期为界线,设置 3 种水分处理,花后不浇水 (W0)、花后浇 1 水(灌浆期,W1)、花后浇 3 水(灌浆期、乳熟期、蜡熟期,W2)。结果表明: 两种类型玉米籽粒蛋白质 及其组分含量的积累动态基本一致，且不受土壤水分供应状况的影响。玉米籽粒蛋白质及清蛋白、谷蛋白含量 均 为 高油 $115^{\prime}$ 较高 球蛋白含量为 掖单 $22^{\prime}$ 较高 醇溶蛋白两类型玉米含量相近。在不同水分供应条件下, 两种类 型玉米叶片中 NRase、GS 酶活性和籽粒中 GS、GDH 酶活性的变化动态一致,NRase 酶活性自灌浆初期至成熟期一直 下降，GS、GDH 酶活性呈单峰曲线，在授粉后 $20 \sim 40 \mathrm{~d}$ 达到高峰，充足的水分供应有利于酶的活性维持较高水平; 王 米叶片中 NRase 酶活性“, 掖单 22' 高于 高油 115’ 叶片 GS 和籽粒 GDH 酶活性显著低于 高油 $115^{\prime}$ 。研究表明 :用 玉米叶片中 NRase 和 GS 活性的高低表征籽粒蛋白质含量的高低不确切, 土壤水分条件与不同类型玉米穗位叶和 籽粒中 GS 和 GDH 活性关系密切。

关键词 水分 玉米 品种类型 蛋白质 酶

\section{EFFECT OF WATER ON PROTEIN , PROTEIN COMPOSITION AND RELATED EN- ZYME ACTIVITY IN DIFFERENT TYPES OF MAIZE}

ZHANG Zhi-Meng $^{1}$, DAI Liang-Xiang ${ }^{1}$, HU Chang-Hao ${ }^{2}$, DONG Shu-Ting ${ }^{2}$, WANG Kong-Jun ${ }^{2}$, and NING Tang-Yuan ${ }^{2}$

${ }^{I}$ Shandong Peanut Research Institute, Qingdao, Shandong 266100, China, and ${ }^{2}$ Department of Agronomy, Shandong Agricultural University, Tai' an , Shandong 271018 , China

Abstract Aims The biosynthesis of maize protein , which is positively correlated to maize grain quality , is controlled by nitrate reductase (NRase), glutamine synthetase (GS), and glutamate dehydrogenase (GDH) , which are affected by genetics and environment. Therefore, cultivation methods and environment affect grain quality in maize ; however, there are few reports of the effects of soil water on maize grain quality and corresponding enzyme activities.

Methods The experiment was carried out in pool culture within a rain-proof shelter using normal maize (Yedan 22) and high oil maize (Gaoyou 115). There were three water treatments : no irrigation after anthesis , irrigation once after anthesis (at grain filling period) and irrigation three times after anthesis (at grain filling period, milky period and wax period).

Important findings Grain protein was higher in Gaoyou115 than Yedan22, and its component contents increased with increasing water supply. With different water supply, the activities of NRase, GS in leaves and GS , GDH in grains exhibited the same trends in the two types of maize. The activity of NRase decreased , and the activities of GS and GDH had unimodal curves , peaking 20 to 40 days after pollination. The activities of these enzymes increased with increased water supply. However , the activity of NRase in leaves of Yedan22 was higher than in Gaoyou115, while the activities of GS in leaves and GDH in grains were reversed , resulting in lower protein content in grains of Yedan22 than in Gaoyou115. The NRase and GS activities in maize leaves did not match grain protein content. Soil water condition was closely related with the activities of GS and GDH 
in ear leaves and grains of different types of maize.

Key words water, maize , variety type , protein , enzyme

高油玉米 (Zay mays L.) 含有丰富的蛋白质、色 氨酸、赖氨酸等多种化合物, 它的遗传增值表现在能 量水平的提高和营养成分的改善, 作为一种粮油饲 兼用型优质玉米其具有较高的利用价值和发展前 景。玉米籽粒主要由淀粉、蛋白质和脂肪等物质组 成，其中蛋白质仅占籽粒干重的 4\% 10\% ,但蛋白 质组分及各组分的分布却是影响玉米品质的重要因 素。蛋白质作为氮素代谢的终极产物,与玉米籽粒 品质呈正相关关系, 其生物合成主要在硝酸还原酶 (NRase)、谷氨酰胺合成酶 (GS)、谷氨酸脱氢酶 (GDH)等一系列酶催化下完成，受制于品种自身遗 传特性及环境因素,栽培管理措施和生态环境条件 对玉米品质具有十分重要的影响。国内外学者对玉 米籽粒品质成分形成的研究报道较多 (王忠孝等, 1986, 1990; 高群英和 Glover, 1994; 高荣歧等,1997； 李金洪和李伯航, 1995;王鹏文等, 1996, 1999; 王鹏 文和刘鹏飞, 1997;刘开昌等,2002; Ingle et al. , 1965 ;Doehlert et al . 1988 ; Doehlert \& Lambert , 1991 ; 王宪泽和张树芹, 1999 张智猛等, 2005 赵俊晔和于 振文,2005 ;曹方等,2005）, 对籽粒中酶活性的分布 亦做了探讨。但关于土壤水分供应状况对玉米籽粒 主要品质成分的分布、积累动态和相关酶活性的影 响的研究尚少见报道。为此, 本研究选取普通玉米 和高油玉米为材料, 探讨了玉米灌浆期不同水分供 应水平对籽粒形成过程中籽粒蛋白质及其组分含量 的动态变化，以及氮素代谢主要调节酶活性的影响， 为制定高产优质栽培措施和培育优质玉米品种提供 科学依据。

\section{1 材料和方法}

\section{1 供试材料与试验处理}

试验在山东农业大学农场进行, 采用防雨棚池 栽试验。以两种不同类型玉米: 普通玉米 掖单 22' 和高油玉米 高油 115 '为研究对象。栽培池面积为 $12 \mathrm{~m}^{2}$, 池深 $1.6 \mathrm{~m}$ 。池子四周用水泥封实, 不封池 底。设滑动式遮雨棚, 常年地下水位在 $13.0 \mathrm{~m}$ 以 下。每池种植 5 行, 行距 $50 \mathrm{~cm}$ 种植密度 67500 株 $\mathrm{hm}^{-2}$,开沟穴播。裂区设计, 灌水处理为主区, 品种 类型为副区，主副区内随机排列，重复 3 次。土壤基 础肥力为有机质 $8.70 \mathrm{~g} \mathrm{~kg}^{-1}$ 、水解氮 $83.29 \mathrm{mg}$ $\mathrm{kg}^{-1}$ 、速效磷 $59.56 \mathrm{mg} \mathrm{kg}^{-1}$ 、速效钾 $73.55 \mathrm{mg}$ $\mathrm{kg}^{-1}$ 。水分处理以开花期为界线, 开花期以前各处 理一致均浇 3 次水，即播种前、大口期、开花初期各 浇 1 次水, 使土壤水分含量自出苗至开花期保持在 $16 \%$ 左右。自开花期始至成熟期，设置 3 种水分处 理 花后不浇水 (W0)、花后浇 1 水(灌浆期, ,W1)、花 后浇 3 水(灌浆期、乳熟期、蜡熟期，W2)。人工控制 浇水, 播前底墒水浇水量均为 $1200 \mathrm{~m}^{3} \mathrm{hm}^{-2}$, 其它 各处理每次浇水量均为 $900 \mathrm{~m}^{3} \cdot \mathrm{hm}^{-2}$, 土壤含水量 采用烘干法测定。

肥料施用 氮肥分两次施用, 播种前底施总量的 $1 / 2$,大口期施 $1 / 2$ 。磷、钾肥播种前一次底施, 其用 量分别为 $\mathrm{N} 450 \mathrm{~kg} \mathrm{hm}^{-2}, \mathrm{P}_{2} \mathrm{O}_{5} 75 \mathrm{~kg} \mathrm{hm}^{-2}, \mathrm{~K}_{2} \mathrm{O} 150$ $\mathrm{kg} \mathrm{hm}{ }^{-2}$ 。管理措施同高产田。

标记开花吐丝期一致的植株，套袋人工授粉。 自开花期始每隔 $10 \mathrm{~d}$ 采取各处理标记植株的穗位 叶各 4 片及相应植株的果穗中部样品, 放入液氮罐 中带回室内, 在 $-40{ }^{\circ} \mathrm{C}$ 冰箱内低温保存, 以备测定 相关生理生化指标。测定前 将叶片去除叶脉后 取 其中部剪碎后用于相关指标测定; 另将果穗中部籽 粒剥离后混匀, 随机取 20 粒用于生理生化指标测 定。

试验数据为 2 年试验的平均值, 采用 DPS2000 数据处理软件分析。

\section{2 测定项目及方法}

\subsection{1 硝酸还原酶活性测定}

称取新鲜材料 $1.0 \mathrm{~g}$ 于试管中，加入 $10 \mathrm{ml}$ 磷酸 缓冲液 $\left(0.1 \mathrm{~mol} \mathrm{~L}^{-1}, \mathrm{pH} 7.5\right)$ 真空充气 $10 \mathrm{~min}$, 中 间放气 2 4 次, 置于暗室 $20 \mathrm{~min}$, 取出后加入 $30 \%$ $\mathrm{Cl}_{3} \mathrm{COOH}$ (TCA) $1 \mathrm{ml}$, 立即振荡 取浸提液 $2 \mathrm{ml}$ 置于 试管中，加入 $4 \mathrm{ml} \%$ 的磺胺溶液和 $4 \mathrm{ml} 0.02 \%$ a-萗 胺溶液 $4 \mathrm{ml}$ 振荡摇匀静置 $35 \mathrm{~min}$, 在 $540 \mathrm{~nm}$ 测定其 吸光值。

\subsection{2 谷氨酰胺合成酶活性测定}

称取新鲜材料 $1.0 \mathrm{~g}$ 于研钵中, 加 $3 \mathrm{ml}$ Tris- $\mathrm{HCl}$ 提取缓冲液, 冰浴研磨后转移至离心管中, $4{ }^{\circ} \mathrm{C}$ 下 $15000 \times \mathrm{g}$ 离心 $20 \mathrm{~min}$,上清液即为粗酶液。显色反 应: $1.6 \mathrm{ml}$ 反应混合液 $\mathrm{B}$, 加入 $0.7 \mathrm{ml}$ 粗酶液和 0.7 $\mathrm{ml}$ ATP 溶液, 混匀, 于 $37^{\circ} \mathrm{C}$ 下保温 $0.5 \mathrm{~h}$, 加 $1 \mathrm{ml}$ 显 色剂, 摇匀放置片刻后，于 $5000 \times \mathrm{g}$ 下离心 $10 \mathrm{~min}$, 取上清液于 $540 \mathrm{~nm}$ 处测定其吸光值，以加入 $1.6 \mathrm{ml}$ 反应混合液 $\mathrm{A}$ 为对照。 
提取液 $0.05 \mathrm{~mol} \mathrm{~L}^{-1}, \mathrm{pH} 8.0$,内含 $2 \mathrm{mmol} \mathrm{L}^{-1}$

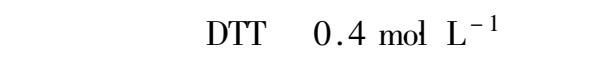

反应混合液 $\mathrm{B}: 80 \mathrm{mmol} \mathrm{L}^{-1}$ 盐酸着胺 $; \mathrm{pH} 7.4$ 的 $0.1 \mathrm{mmol} \mathrm{L}^{-1}$ Tris-HCl 缓冲液内含 $80 \mathrm{mmol} \mathrm{\textrm {L } ^ { - 1 }}$ $\mathrm{Mg}^{2+}, 20 \mathrm{mmol} \mathrm{L}{ }^{-1}$ 谷氨酸钠盐, $20 \mathrm{mmol} \mathrm{L} \mathrm{L}^{-1}$ 半胱氨 酸和 $2 \mathrm{mmol} \mathrm{L}^{-1}$ 乙二醇 $=$ 乙醚 $=$ 胺四乙酸 $($ EGTA $)$ 。

显色剂: 0.2 mol $\mathrm{L}^{-1} \mathrm{TCA}, 0.37 \mathrm{~mol} \mathrm{~L}^{-1} \mathrm{FeCl}_{3}$

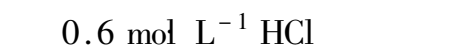

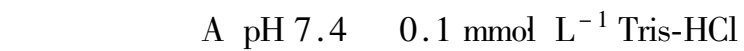
缓冲液内含 $80 \mathrm{mmol} \mathrm{L} \mathrm{L}^{-1} \mathrm{Mg}^{2+}, 20 \mathrm{mmol} \mathrm{L} \mathrm{L}^{-1}$ 谷氨酸 钠盐, $20 \mathrm{mmol} \mathrm{L} \mathrm{L}^{-1}$ 半胱氨酸和 $2 \mathrm{mmol} \mathrm{L^{-1 }}$ EGTA。

\subsection{3 谷氨酸脱氢酶活性测定}

称取新鲜材料 $1.0 \mathrm{~g}$ 于研钵中, 加 $8 \mathrm{ml}$ 提取液 冰浴研磨 转移到 $10 \mathrm{ml}$ 离心管中, $4^{\circ} \mathrm{C}, 20000 \times g$ 离心 $20 \mathrm{~min}$,上清液即为粗酶液。酶活性测定: $1 \mathrm{ml}$ 酶提取液 $+2 \mathrm{ml}$ 反应液 $\mathrm{B}$, 以加反应液 $\mathrm{A}$ 为对照于 $340 \mathrm{~nm}$ 处比色, 每隔 $1 \mathrm{~min}$ 记录一次吸光度 $(\mathrm{OD})$ 值, 共记录 4 次。

提取液: $0.2 \mathrm{mmol} \mathrm{L}^{-1}$ Tris- $\mathrm{HCl}$ 缓冲液, $\mathrm{pH}$ 值 8.2 。

反应液 $\mathrm{A}: 1.6 \mu \mathrm{mol} \mathrm{L}^{-1} \mathrm{NAD}$ 和 $360 \mu \mathrm{mol} \mathrm{L}^{-1}$ Tris-HCl 缓冲液。

反应液 $\mathrm{B}: 60 \mu \mathrm{mol} \mathrm{L}^{-1} \mathrm{~L}$-谷氨酸和 $1.6 \mu \mathrm{mol}$ $\mathrm{L}^{-1} \mathrm{NAD}$ 和 $360 \mu \mathrm{mol} \mathrm{L} \mathrm{L}^{-1}$ Tris-HCl 缓冲液。

\subsection{4 蛋白质含量的测定方法}

采用半微量凯氏定氮法。

\subsection{5 蛋白质组分提取和分析方法}

参照何照范 (1986) 的方法。称取样品 $0.5 \mathrm{~g}$ 置 于研钵中, 按照清蛋白、球蛋白、醇溶蛋白和谷蛋白 的顺序提取。

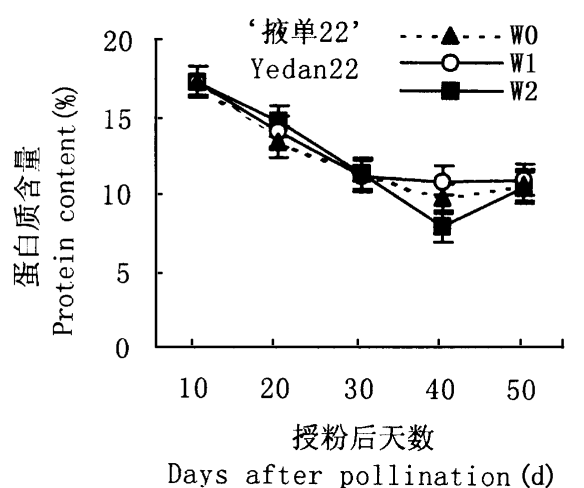

清蛋白的提取采用蒸馏水, 球蛋白的提取用 $10 \% \mathrm{NaCl}, 75 \% \quad \mathrm{C}_{2} \mathrm{H}_{5} \mathrm{OH}$ 提取醇溶蛋白, $0.2 \% \mathrm{NaOH}$ 提取谷蛋白。

\section{2 结果分析}

\section{1 水分处理对两种类型玉米籽粒蛋白质含量的 影响}

图 1 表明，两种类型玉米各处理籽粒蛋白质含 量均以授粉初期授粉后 $10 \mathrm{~d}$ 最高, 以后逐渐下降, 至成熟期略有升高的变化趋势。不同水分供应状况 并未使玉米籽粒蛋白质含量表现明显差异,但花后 干旱处理 (W0) 使 高油 $115^{\prime}$ 在授粉后 $30 \mathrm{~d}$ 籽粒蛋 白质含量显著高于其它两种水分处理 (W2、W1) , 授 粉后 $40 \mathrm{~d}$,充足的水分供应 (W2) 使 掖单 $22^{\prime}$ 籽粒蛋 白质含量降至最低。同一时期籽粒蛋白质含量 高 油 $115^{\prime}$ 略高于 掖单 $22^{\prime}$ 。

\section{2 玉米籽粒蛋白质组分含量的变化}

2.2.1 水分处理对两种类型玉米籽粒清蛋白和球 蛋白含量的影响

由图 2 所示, 籽粒灌浆期间两种类型玉米籽粒 清蛋白含量逐渐下降, 授粉后 $10 \sim 20 \mathrm{~d}$, 其中 掖单 22'下降较为迅速，之后下降较为缓慢。土壤水分供 应状况对两种类型玉米籽粒清蛋白含量影响不同， W0 处理 掖单 22' 在授粉后 $20 \sim 50 \mathrm{~d}$ 的籽粒淀粉含 量基本稳定在 3\% 4\% 之间。”高油 115 '则一直呈 下降趋势。”掖单 22 '在授粉后 $40 \mathrm{~d}$ 以前 W2 处理 最高, W1 与 W0 相近, 成熟期 W0 处理最高“; 高油 $115^{\prime}$ 在授粉后 $20 \mathrm{~d}$ 以前 $\mathrm{W} 2$ 最低, 成熟期三处理相 近。可见灌浆期土壤水分状况对玉米籽粒清蛋白含 量的影响较大。

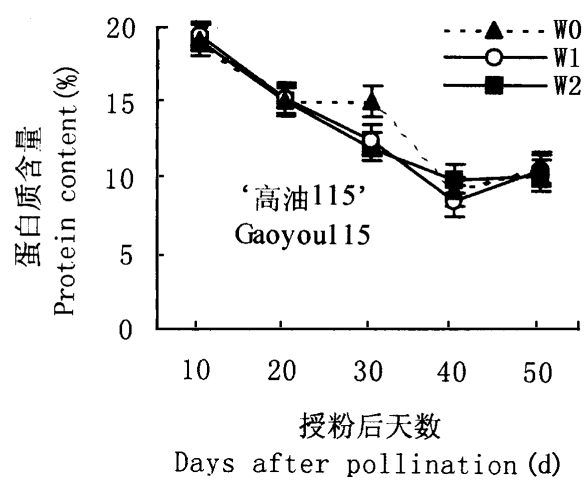

图 1 不同水分处理对两种类型玉米籽粒蛋白质含量的影响

Fig.1 Effect of different water treatments on protein content in grain of two types of maize

W0 : 花后不浇水 No water irrigated after anthesis W1:花后浇 1 水 Irrigated one time after anthesis W2:花后浇 3 水 Irrigated three times after anthesis 

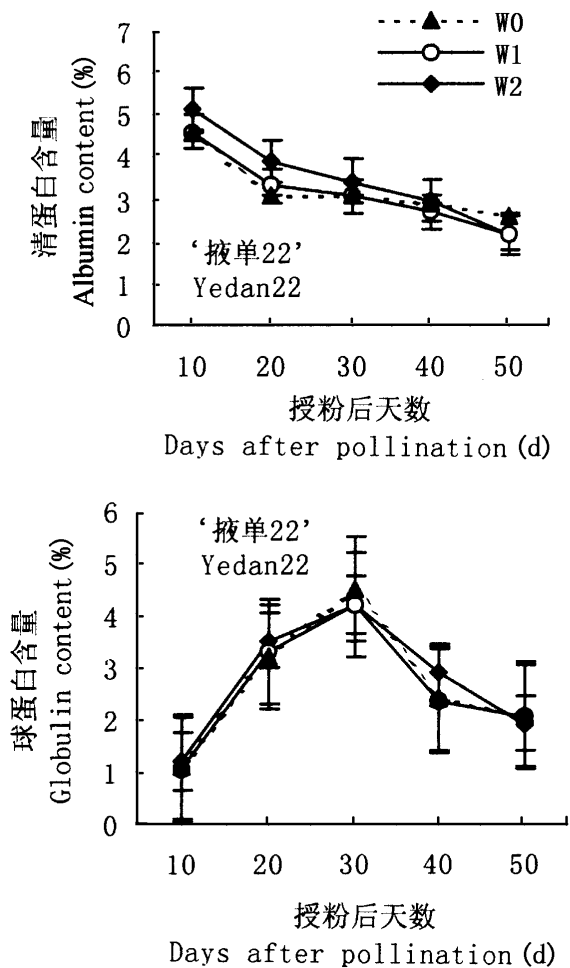
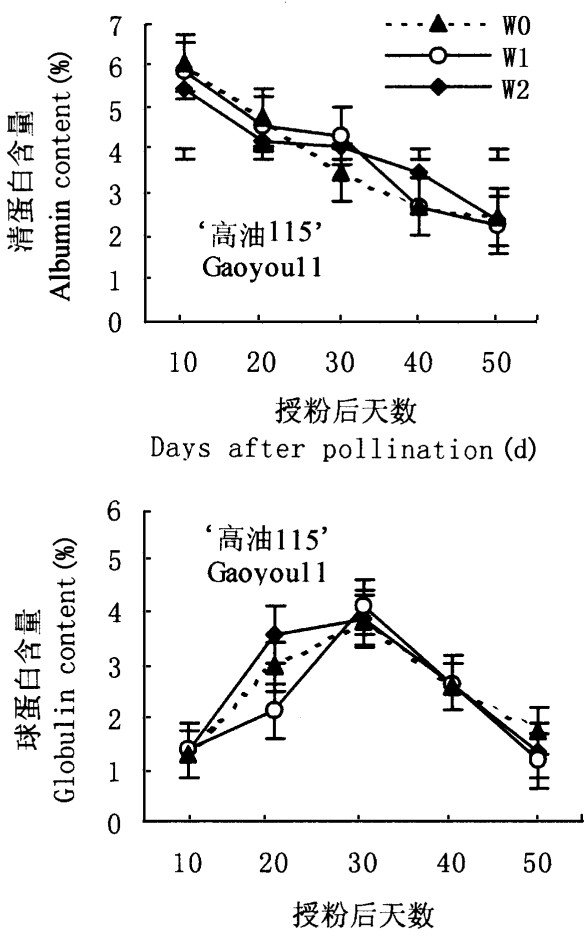

Days after pollination(d)

图 2 不同水分处理对两种类型玉米籽粒清蛋白和球蛋白含量的影响

Fig.2 Effect of different water treatments on the albumin and globulin content in grain of two types of maize W0、W1、W2 : 见图 1 See Fig. 1

两种类型玉米籽粒球蛋白含量均呈单峰曲线 变化,开花后逐渐上升，在授粉后 $30 \mathrm{~d}$ 达到峰值，而 后逐渐下降', 掖单 $22^{\prime}$ 上升速率较快 ;土壤水分供 应状况对 掖单 $22^{\prime}$ 籽粒球蛋白的影响作用不大，对 高油 115 ’ 灌浆前期略有影响, 而后期差异不明显。

2.2 .2 水分处理对两种类型玉米籽粒醇溶蛋白和 谷蛋白含量的影响

醇溶蛋白和谷蛋白主要存在于淀粉体中,成为 籽粒的储藏蛋白，对籽粒的营养品质影响较大。

图 3 表明，在整个灌浆期间，两种类型玉米籽粒 醇溶蛋白含量变化为 V" 字形曲线, 峰谷出现在授 粉后 $30 \mathrm{~d}$ 。水分供应状况对两种类型玉米籽粒醇溶 蛋白含量的影响作用不同“，掖单 22’ 籽粒醇溶蛋白 的积累受土壤水分供应状况影响不大', 高油 115 ' 则受其影响较大, 适宜的土壤含水量更有利于 高油 $115^{\prime}$ 籽粒醇溶蛋白的积累。因此, 在普通玉米和高 油玉米高产优质栽培管理措施上应有区别。

玉米籽粒谷蛋白的含量，在灌浆期间均呈上升 趋势。“掖单 22' 灌浆前期上升速率较快, 后期较为 缓慢'; 高油 $115^{\prime}$ 上升速率一直较高。土壤水分供 应状况对两种玉米籽粒谷蛋白的影响作用不同，灌 浆前期“, 掖单 22 ' 以 $\mathrm{W} 1$ 处理最高, $\mathrm{W} 0$ 和 $\mathrm{W} 2$ 处理
相近“; 高油 115 ’则以 $\mathrm{W} 0$ 处理最高, 其次为 W2 处 理, W1 处理最低, 此期“, 高油 115 ’ 籽粒谷蛋白含量 受土壤水分供应状况的影响较大。授粉后的第 $30 \mathrm{~d}$ 以后, 两种玉米籽粒谷蛋白含量均以 $\mathrm{W} 2$ 处理最高, 此期 掖单 22' 对土壤水分的反应较为敏感。可见， 土壤水分供应状况对玉米籽粒咜藏蛋白的影响差异 较大，干旱利于 高油 $115^{\prime}$ 灌浆前期咜藏蛋白的合 成，后期有抑制作用“，掖单 22’ 在整个灌浆过程中 一直处于抑制状态，说明玉米籽粒蛋白质含量不仅 与环境因素有关, 而且与自身的遗传因素密切相连。

2.3 水分处理对两种类型玉米叶片硝酸还原酶活 性酶活性的变化

NRase 是植物氮代谢的关键酶，催化 $\mathrm{NO}_{3}{ }^{-}$转化 为氨基酸的第一步反应, 它有较大的 $K_{m}$ 值, 因而又 是一种限速酶，直接影响到蛋白质的合成。同时， NRase 本身也是蛋白质, 其活性主要靠酶蛋白合成 来维持，所以，叶片中 NRase 活性的强弱在一定程度 上反映了蛋白质合成和氮代谢活性。NRase 是诱导 酶，因而受光照、氮素、水分等环境因素的影响。

\subsection{1 玉米穗位叶硝酸还原酶活性的变化}

由图 4 可以看出,开花后两类型玉米穗位叶 NRase 酶活性的变化趋势均随时间的推移而下降。 
整个灌浆期间“, 掖单 22 ’ 的酶活性较高,下降速率 较快“; 高油 115 ’ 穗位叶 NRase 酶活性相对较低, 开 花始期至花后 $20 \mathrm{~d}$, 其活性降低较为迅速, 花后 $30 \mathrm{~d}$ 略有升高, 而后又缓慢下降。水分处理对两类型玉 米穗位叶 NRase 酶活性的作用不同“, 掖单 22’ 灌浆 前期受水分处理影响较大, 而 高油 115' 则在花后 $20 \mathrm{~d}$ 至成熟受水分处理影响较大, 两类型玉米均表
现为 W2 处理叶片 NRase 酶活性较高“, 掖单 22’ 的 W1 和 W0 处理的叶片 NRase 酶活性相近', 高油 $115^{\prime}$ 则以 $\mathrm{W} 0$ 处理较低; 同一时期, 不同水分处理的 NRase 活性“，掖单 22' 高于 高油 115’。表明灌浆期 充足的土壤水分供应有利于玉米穗位叶 NRase 酶活 性的提高，土壤干旱降低了玉米叶片 NRase 酶活性， 不利于植株体内蛋白质的合成和氮代谢过程。

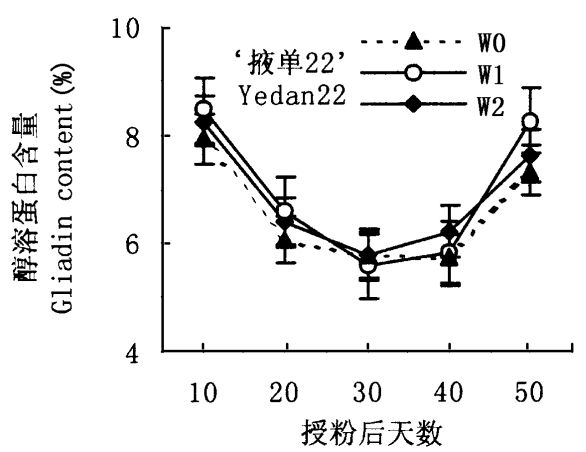

Days after pollination(d)

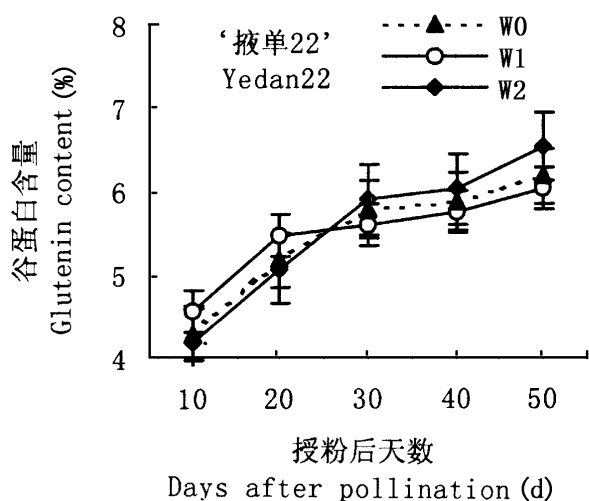

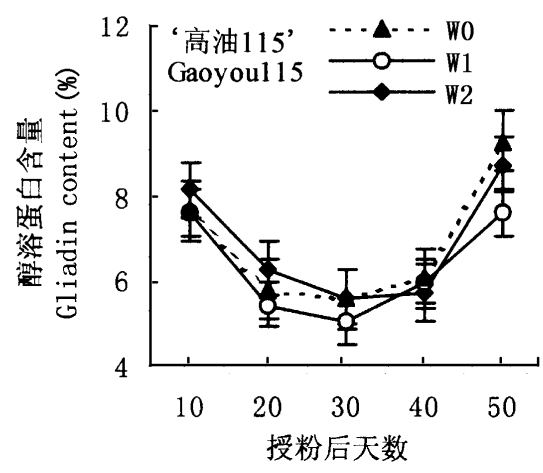

Days after pollination(d)

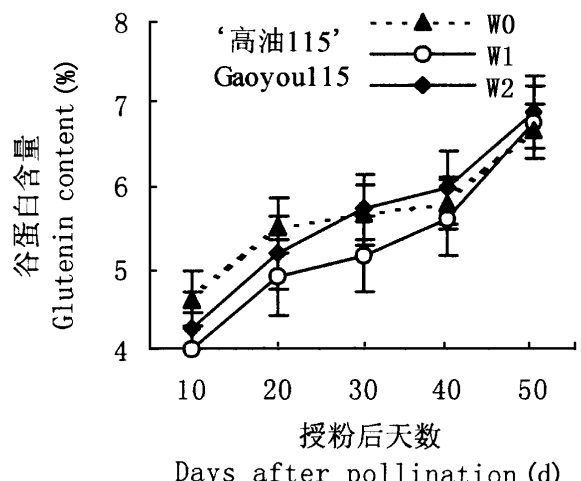

Days after pollination(d)

图 3 不同水分处理对两种类型玉米籽粒醇溶蛋白和谷蛋白含量的影响

Fig.3 Effect of different water treatments on the glutenin and gliadin content in grain of two types of maize W0、W1、W2 : 见图 1 See Fig. 1
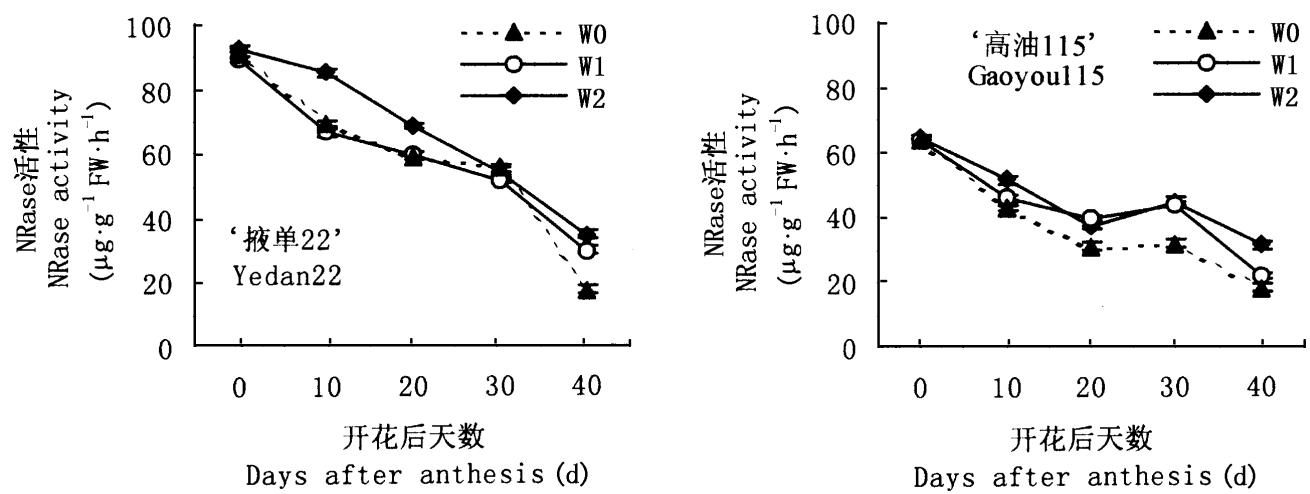

图 4 不同水分处理对两种类型玉米穗位叶硝酸还原酶 (NRase)活性的影响

Fig.4 Effect of different water treatments on NRase activity in ear leaves of two types of maize W0、W1、W2 : 见图 1 See Fig. 1 


\subsection{2 玉米穗位叶谷氨酰胺合成酶活性的变化}

GS 是处于氮代谢中心的多功能酶, 参与多种氮 代谢的调节, 它的主要作用催化 $\mathrm{NH}_{4}{ }^{+}$和谷氨酸 (Glu) 合成谷氨酰胺 (Gln),GS 活性降低可使细胞内 多种氮代谢酶和部分糖代谢受到严重影响。

由图 5 可以看出,在整个灌浆期,两种类型玉米 穗位叶 GS 活性变化均为单峰曲线, 峰值均出现在 授粉后 $20 \mathrm{~d}$, 其中 高油 $115^{\prime}$ 峰值较高, GS 活性的上 升和下降速度较快', 掖单 22 ' 的峰值较低, 上升和 下降速度较慢, 表明两种类型玉米 源”端物质同化、 运输等的差异“, 高油 115 ' 叶片具有较强的氮代谢 能力。授粉后 $20 \mathrm{~d}$, 两类型玉米 W2 处理均显著的 提高穗位叶中 GS 活性, 土壤干旱致使叶片中 GS 活 性降低，从而抑制了植株体内氮代谢的速度和强度， 影响籽粒蛋白质的积累。

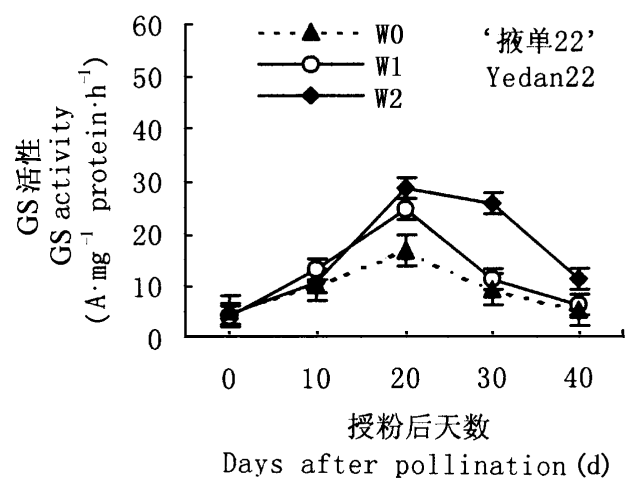

2.4 水分处理对两种类型玉米籽粒谷氨酰胺合成 酶活性、谷氨酸脱氢酶活性的变化

\subsection{1 谷氨酰胺合成酶活性变化}

由图 6 可以看出 授粉后两类型玉米籽粒 GS 活 性的变化趋势一致, 均呈单峰曲线, 授粉后酶活性快 速上升, 在授粉后 $20 \mathrm{~d}$ 达到峰值, 而后逐渐下降, 但 高油 115 ’ 峰值明显低于 掖单 22’。授粉后 10２0 $\mathrm{d}$, 水分处理对两种类型籽粒 GS 活性几乎无影响; 在授粉后 $20 \mathrm{~d}$ 至成熟时，水分对玉米籽粒 GS 活性 的影响较大', 掖单 22 ' 表现为 W2 $>\mathrm{W} 1>\mathrm{W} 0$ “, 高油 $115^{\prime}$ 以 W0 最低, 但 W2 和 W1 两处理的籽粒 GS 活 性相近。表明充足的土壤水分供应使玉米籽粒 GS 活性在灌浆后期提高, 土壤干旱使两种类型玉米籽 粒 GS 活性显著降低,土壤水分状况是影响植株体 内氮代谢的重要因素。

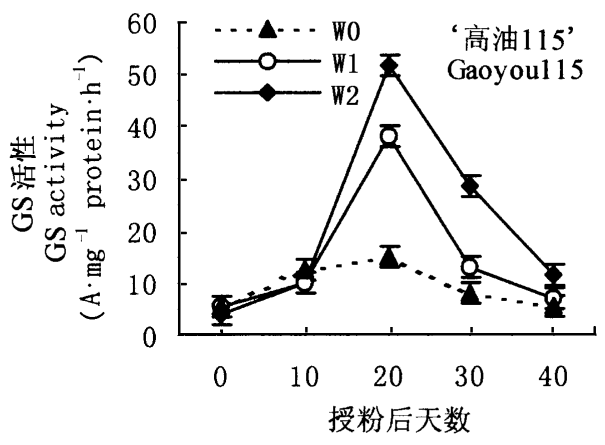

Days after pollination(d)

图 5 不同水分处理对两种类型玉米穗位叶谷氨酰胺合成酶 (GS)活性的影响

Fig.5 Effect of different water treatments on GS activity in ear leaves of two types of maize W0、W1、W2 : 见图 1 See Fig. 1

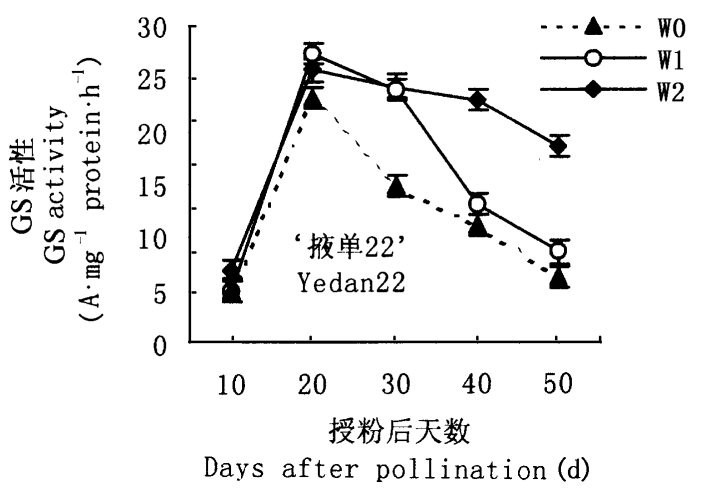

图 6 不同水分处理对两种类型玉米籽粒谷氨酰胺合成酶 (GS)活性的影响

Fig.6 Effect of different water treatments on GS activity in grains of two types of maize W0、W1、W2 : 见图 1 See Fig. 1 


\subsection{2 谷氨酸脱氢酶活性变化}

$\mathrm{GDH}$ 一般参与了氨基酸降解过程中的氧化脱 氨作用, 要求较高的氨浓度才能进行氨同化。当作 物遇到环境胁迫或在自然衰老过程中，GDH 在氨的 再同化中起重要作用, 尤其是在作物籽粒灌浆后期 对于催化合成谷氨酸具有重要作用, 因此,GDH 活 性的高低直接影响到作物籽粒蛋白质的合成。

由图 7 可以看出, 开花授粉后, 两种类型玉米籽 粒 GDH 活性均快速上升，在授粉后 $40 \mathrm{~d}$ 达到高峰， 而后迅速下降。水分处理对两种类型玉米籽粒 GDH 活性的影响作用相同，授粉后 $10 \sim 20 \mathrm{~d}, 3$ 种水 分处理间 GDH 活性非常相近,之后，处理间差异逐
渐增大至授粉后 $50 \mathrm{~d}$ 此期两类型玉米 GDH 活性均 表现为 W2 > W1 > W0 ; 同一时期“, 高油 115’ 籽粒 GDH 活性略高于 掖单 22'。表明花后灌水可提高 灌浆中后期籽粒中 GDH 活性, 土壤干旱使籽粒 GDH 活性明显降低。

\section{5 水分处理对两种类型玉米籽粒产量的影响}

由表 1 可以看出，水分处理对两类型玉米产量 及产量构成因素均有显著影响, 表现为 $\mathrm{W} 2>\mathrm{W} 1>$ W0。水分处理主要通过影响粒重而影响产量, 从各 水分处理的平均产量看“, 掖单 $22^{\prime}$ 比 高油 $115^{\prime}$ 高 $17.32 \%$ 。
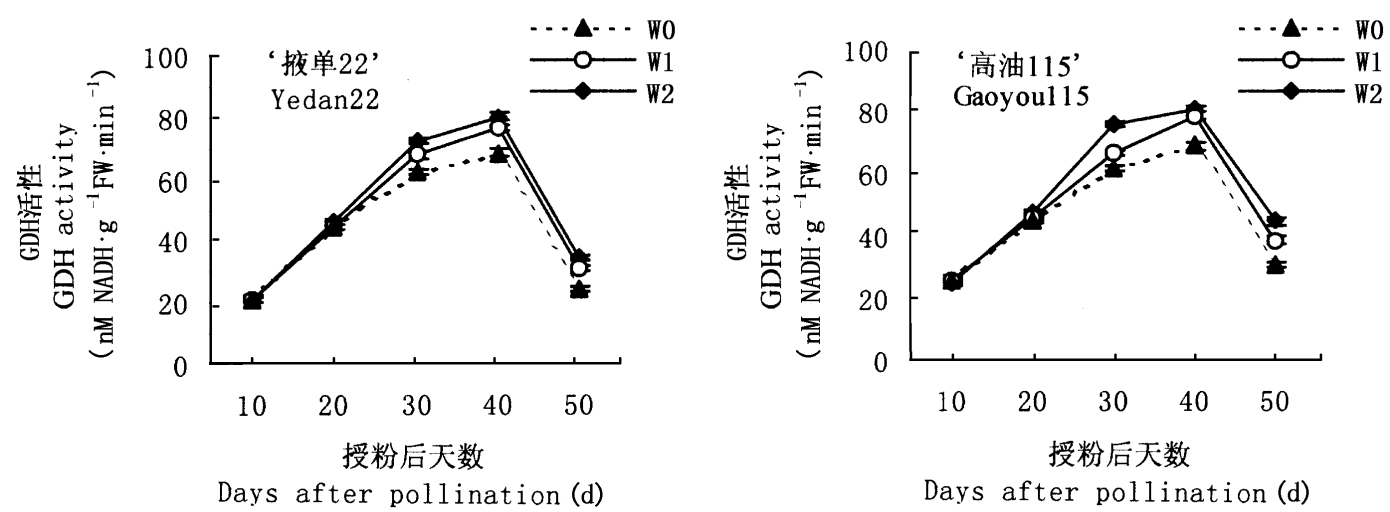

图 7 不同水分处理对两种类型玉米籽粒谷氨酸脱氢酶 (GDH)活性的影响

Fig.7 Effect of different water treatments on GDH activity in ear leaves of two types of maize W0、W1、W2 : 见图 1 See Fig. 1

表 1 不同水分处理对两种类型玉米籽粒产量及构成因素的影响

Table 1 Effect of different water treatments on yield of two types of maize

\begin{tabular}{cccccc}
\hline $\begin{array}{c}\text { 品种 } \\
\text { Variety }\end{array}$ & $\begin{array}{c}\text { 水分处理 } \\
\text { Water treatment }\end{array}$ & $\begin{array}{c}\text { 穗粒数 } \\
\text { No. of kernel per ear }\end{array}$ & $\begin{array}{c}\text { 千粒重 } \\
\text { Wt. of } 1000 \text { kernels }(\mathrm{g})\end{array}$ & $\begin{array}{c}\text { 穗粒重 } \\
\text { Wt. per ear }(\mathrm{g})\end{array}$ & $\begin{array}{c}\text { 产量 } \\
\text { Yield }\left(\mathrm{kg} \mathrm{hm}{ }^{-2}\right)\end{array}$ \\
\hline ‘掖单 22 & W2 & $448.00^{\mathrm{a}}$ & $362.76^{\mathrm{a}}$ & $159.50^{\mathrm{a}}$ & $9130.09^{\mathrm{a}}$ \\
Yedan22 & W1 & $414.00^{\mathrm{b}}$ & $350.80^{\mathrm{b}}$ & $150.00^{\mathrm{b}}$ & $8815.26^{\mathrm{b}}$ \\
& W0 & $398.40^{\mathrm{c}}$ & $317.02^{\mathrm{c}}$ & $123.00^{\mathrm{c}}$ & $6869.03^{\mathrm{c}}$ \\
‘ 高油 115' & W2 & $468.48^{\mathrm{a}}$ & $292.54^{\mathrm{a}}$ & $139.00^{\mathrm{a}}$ & $7956.63^{\mathrm{a}}$ \\
Gaoyou115 & W1 & $401.28^{\mathrm{b}}$ & $267.52^{\mathrm{b}}$ & $127.20^{\mathrm{b}}$ & $7269.72^{\mathrm{b}}$ \\
& W0 & $404.46^{\mathrm{c}}$ & $233.40^{\mathrm{c}}$ & $106.90^{\mathrm{c}}$ & $5924.54^{\mathrm{c}}$ \\
\hline
\end{tabular}

同一列中 $a 、 b 、 c$ 表示差异达 5\%显著水平 $\mathrm{a}, \mathrm{b}, \mathrm{c}$ means signification at 5\% level W0、W1、W2 : 见图 1 See Fig. 1

\section{3 讨 论}

\section{1 两类型玉米品种籽粒蛋白质含量与氮代谢酶} 活性的关系

NRase 是植物氮素同化的关键酶, 其活性的高 低影响植物氮水平，也与植物的耐肥性有密切关系。 NRase 活性与籽粒蛋白质含量的关系, 前人的研究
结论很不一致。一般情况下, 蛋白质含量高和产量 较高的作物品种具有较高的 NRase 活性且衰退缓慢 的特点(朱德群等, 1991) , 小麦开花后叶片 NRase 活 性是反映籽粒蛋白质含量高低的一项重要指标 (Dalling et al . 1976) , 硝酸还原酶活性与籽粒产量 和蛋白质含量呈正相关 (Deckard et al . 1984)。但 是, 也有一些研究认为 NRase 活性与籽粒蛋白质含 
量相关不显著,并认为高蛋白品种一般具有高的硝 酸还原酶活性,但并非硝酸还原酶活性高的品种蛋 白质含量也一定高 (Dalling et al. , 1976)。处于氨 同化中心作用的谷氨酰胺合成酶具有转化酶和合成 酶两种酶功能活性，其活性的提高有利于植物铵同 化和氮素转运(Becker et al. ,2000; González et al. , $2000)$ 。氮效率高的品种功能叶中 GS 活性明显高于 氮低效率品种(刘强等, 2001)。本研究表明, 普通玉 米 掖单 22' 叶片中 NRase 活性高于 高油 115', 而 叶片 GS 和籽粒 GDH 酶活性均低于 高油 115'表明 NRase 和 GS 活性与品种籽粒蛋白质含量并不完全 一致，尽管 掖单 $22^{\prime}$ 在 $\mathrm{NO}_{3}{ }^{-}-\mathrm{NH}_{4}{ }^{+}$阶段具有较高的 同化能力, 但在 $\mathrm{NH}_{4}{ }^{+}-\mathrm{Gln}$ 阶段的同化能力和籽粒灌 浆后期氮的再同化利用能力却下降, 可能导致了掖 单 $22^{\prime}$ 籽粒中蛋白质含量低于 高油 $115^{\prime}$ 。”掖单 $22^{\prime}$ 籽粒中蛋白质含量显著低于 高油 $115^{\prime}$, 主要因 为醇溶蛋白和清蛋白含量的差异而致, 谷蛋白和球 蛋白含量相差并不显著。

3.2 玉米开花后水分供应状况对氮代谢酶活性的 影响

花后灌水情况影响玉米穗位叶 NRase、GS 的活 性，其活性高低随灌水量的增加而提高，籽粒 GS 和 GDH 活性亦受水分处理的影响，因此表明，土壤水 分供应状况对玉米氮代谢关键酶活性的调控效果较 为显著, 充足的水分供应可以显著提高玉米功能叶 的 NRase、GS 活性, 以及灌浆中后期玉米籽粒 GS 和 GDH 活性，土壤干旱明显降低玉米叶片和籽粒各关 键酶的活性。可以认为土壤水分适宜有利于蛋白质 的生物合成与累积。

两种类型玉米叶片中 NRase 活性对土壤水分供 应状况的反映趋势虽表现一致, 但又存在差异“, 掖 单 22' 在灌浆前期对土壤水分供应较敏感, 高油 $115^{\prime}$ 则在后期差异较明显, 这可能是不同类型玉米 籽粒蛋白质含量差异的生理基础。叶片 GS 活性在 授粉后 $10 \mathrm{~d}$ 以前, 随水分供应强度变化, 两种类型 玉米叶片 GS 活性均未表现出明显差异, 这是叶片 GS 的自然反应还是其它原因造成的，有待于进一 步研究。在授粉后 $20 \mathrm{~d}$ 充分供水处理叶片 GS 活性 显著高于花后不供水处理, 说明缺水可能引起叶绿 体基粒片层蛋白减少, 影响了 GS 在翻译水平上的 功能, 导致 GS 活性下降。授粉后 20 30 d 正是籽 粒快速积累蛋白质时期, 叶片中 NRase 活性和 GS 活 性因土壤水分供应水平降低而显著下降, 可能是缺 水导致籽粒蛋白质含量下降的重要生理原因之一。
籽粒中 GS 和 GDH 酶活性在氨、基酸转化成蛋白 质中起着重要作用。不同水分处理两种酶的活性在 玉米籽粒中的动态变化均呈单峰曲线, 但峰值出现 的时期不同，反映了两种酶在籽粒蛋白质合成中所 起的作用不同。GS 催化 $\mathrm{NH}_{4}{ }^{+}$形成合成蛋白质的直 接底物谷氨酰胺, 而 GDH 在籽粒灌浆后期蛋白质合 成起着重要作用 (Kniep \& Mason, 1991 ; Larkins et al . 1976 ; Srivastava \& Singh ,1987) ,并且遇到环境胁 迫时参与 $\mathrm{NH}_{4}{ }^{+}$的再合成 (Loulakakis et al ，1994)， 因而在玉米籽粒灌浆后期 GDH 活性升高有其生理 原因。本试验中玉米籽粒蛋白质含量在后期增高可 能与 GDH 酶活性升高有关。充分供水使玉米籽粒 中的 GS、GDH 活性维持较高水平, 蛋白质合成正常 进行, 缺水条件下两种酶活性迅速降低, 这可能与 GS、GDH 酶蛋白合成数量减少有关, GDH 对 $\mathrm{NH}_{4}{ }^{+}$的 再同化作用减弱，致使玉米籽粒中蛋白质的生物合 成受阻, 蛋白质含量降低, 这与缺水条件下,玉米籽 粒产量降低一致。

\section{参 考 文 献}

Becker TW, Carrayol E, Hirel B (2000). Glutamine synthetase and glutamate dehydrogenase isoforms in maize leaves: localization, relative proportion and their role in ammonium assimilation or nitrogen transport. Planta, 211, 800-806.

Cao Y(曹云), Fan XR(范晓荣), Jia LJ(贾莉君), Yin XM(尹 晓明), Shen QR(沈其荣) (2005). Comparison of nitrate utilization by four different rice (Oryza sativa L.) cultivars. Journal of Nanj̈ng Agriculture University (南京农业大学学报), 28 (1), 52 - 56. (in Chinese with English abstract)

Dalling MJ, Boland G, Willson JH (1976). Relation between acid proteinase activity and redistribution of nitrogen during grain development in wheat. Australian Journal of Plant Physiology, 3, $721-730$.

Deckard EL, Tsai CY, Tucker TC (1984). Effect of nitrogen nutrition on quality of agronomic crop. In: Hauck RD ed. Nitrogen in Crop Production. American Soybean Association, Madison, USA, $601-626$.

Doehlert DC, Lambert RJ (1991). Metabolic characteristics associated with starch, protein, and oil deposition in developing maize kernels. Crop Science, 31,151-157.

Doehlter DC, Kuo TM, Felker FC (1988). Enzymes of sucrose and hexose metabolism in developing kernels of two inbreds of maize. Plant Physiology, 86,1013-1019.

Gao QY(高群英), Glover DV (1994). The relationship of DNA content in corn endosperm nuclei to kernel traits during kernel development. Acta Agronomica Sinica (作物学报), 20 (1), 46 - 51. (in Chinese with English abstract)

Gao RQ(高荣岐), Dong ST(董树亭), Hu CH(胡昌浩), Wang 
QY (王群瑛) (1997). Ultrastructure changes durings cutellar development in maize (Zea mays L.). Acta Agronomica Sinica (作物学报), 23, 232 - 236. (in Chinese with English abstract) González-Moro B, Mena-Petite A, Lacuesta M, González-Murua C, Muñoz-Rueda A (2000). Glutamine synthetase from mesophyll and bundles heath maize cells: isoenzyme complements and different sensitivities to phosphinothricin. Plant Cell Reports, 19, 1127 - 1134 .

He ZF (何照范) (1986). Analysis of Grain and Oil Quality (粮油 品质分析). Science Press, Beijing, 76-115. (in Chinese)

Ingle J, Beitz D, Hageman RH (1965). Changes in composition during development and maturation of maize seeds. Plant Physiology, 40, $835-839$.

Kniep KR, Mason SC (1991). Lysine and protein content normal and opaque-2 maize grain as influenced by irrigation and nitrogen. Crop Science, 31, $177-181$.

Larkins BA, Bracker CE, Tsai CY (1976). Storage protein synthesis in maize: isolation of zein-synthesizing polyribosomes. Plant Physiology, 57, 740-745.

Li JH (李金洪), Li BH (李伯航) (1995). Effects of mineral nutrition on quality of maize grain. Maize Science (玉米科学), (3) , 15 - 18. (in Chinese with English abstract)

Liu KC (刘开昌), Hu CH (胡昌浩), Dong ST (董树亭), Wang KJ (王空军), Wang QC (王庆成), Li AQ (李爱芹) (2002). Accumulation of main quality components in kernels of high oil and high starch maize and their physiological and biochemical characteristics. Acta Agronomica Sinica (作物学报), 28, 492 - 498. (in Chinese with English abstract)

Loulakakis KA, Roubelakis-Angelakis KA, Kanellis AK (1994). Regulation of glutamate dehydrogenase and glutamine synthetase in avocado fruit during development and ripening. Plant Physiology, 106, $212-222$.

Lui Q(刘强), Rong XM(荣湘民), Zhu HM(朱红梅), Peng JW (彭建伟), Lu XY(卢向阳), Chen JB(陈静彬) (2001). Nitrogen metabolism of different rice cultivars under different cultivations. Journal of Hunan Agricultural University (Natural Sciences Edition) (湖南农业大学学报 (自然科学版)), 27 , 415 - 420. ( in Chinese with English abstract)

Srivastava HS, Singh RP (1987). Role and regulation of L-glutamate dehydrogenase activity in higher plants. Phytochemisty, 26, $597-601$.

Wang PW (王鹏文), Lui PF (刘鹏飞) (1997). Researches on the changes of kernel content of maize among 4 plant densities dring flling-maturing stage. Jilin Agricultural Sciences (吉林农 业科学), 41-47. (in Chinese with English abstract)

Wang PW (王鹏文), Dai JY (戴俊英), Zhang M (张明) (1996). The change of amounts of poteins and amino aids in gains in the course of maizs maurity. Journal of Shenyang Agricultural University (沈阳农业大学学报)，(2)，103-106. (in Chinese with English abstract)

Wang PW (王鹏文), Dai JY (戴俊英), Wei YP (魏云鹏) (1999). The effects of drought stress on yield and quality of maize. Journal of Maize Sciences (玉米科学), (Suppl.), 102 - 106. (in Chinese with English abstract)

Wang XZ (王宪泽), Zhang SQ (张树芹) (1999). Study on the relation of NRA and nitrogen accumulation in leaves of different pro-teincontent wheats. Acta Botanica Boreali-Occidentalia Sinica (西北植物学报), 19, 315 - 320. (in Chinese with English abstract)

Wang ZX(王忠孝), Gao XZ(高学曾), Xu JF(许金芳), Liu YJ (刘玉敬), Luo YN (罗瑶年) (1986). A study on the grain abortion of maize (Zea mays L.). Scientia Agricultura Sinica (中国农业科学), (6), 36-40. (in Chinese with English abstract)

Wang ZX (王忠孝), Du CG (杜成贵), Wang QC (王庆成) (1990). Changes in main components of different types of maize hybrids during grain-filling stage. Plant Physiology Communications (植物生理学通讯), (1), 30-33. (in Chinese)

Zhang ZM (张智猛), Dai LX (戴良香), Hu CH (胡昌浩), Dong ST (董树亭), Wang KJ (王空军) (2005). Effects of nitrogen on the protein protein constituents and relevant enzymes activity of maize. Plant Nutrition and Fertilizer Science (植物营 养与肥料学报). $11,320-326$. (in Chinese with English abstract)

Zhao JY (赵俊晔), Yu ZW (于振文) (2005). Effect of nitrogen fertilizer rate on nitrogen metabolism and protein synthesis of superior and inferior wheat kernel. Scientia Agricultura Sinica (中 国农业科学), 38, 1547 - 1554. (in Chinese with English abstract)

Zhu DQ (朱德群), Zhu XL (朱遐龄), Wang Y (王雁), Qi BZ (祁葆滋) (1991). Several physiological parameters in relation to grain protein content in winter wheat (Triticum aestivum). Acta Agronomica Sinica (作物学报), 17(2), 57 - 66. (in Chinese with English abstract) 